\title{
Caracterização de bens culturais por espectroscopia de fluorescência de raios $X$
}

Augusto Câmara Neiva*, Jérémie Dron**

Escola Politécnica da Universidade de São Paulo (Poli/USP)

Departamento de Engenharia Química

LEC (Laboratório de Eletroquímica e Corrosão)

Tel.: +(55) (11) 309-2228; fax: (55)(11) 3031-3020

www.poli.usp.br

\section{Resumo}

O presente trabalho descreve o espectômetro EDXRF desenvolvido pelo LEC/USP para caracterização de peças de aço produzidas na primeira siderúrgica brasileira, a Fábrica Ipanema, e de peças metálicas da coleção pré-hispânica do Museu de Arqueologia e Etnologia da USP. Os procedimentos para quantificação aproximada de titânio nas peças de Ipanema, e para identificação de eventuais elementos minoritários nas ligas de ouro-cobre-prata das peças pré-hispânicas, bem como os resultados alcançados, são aqui analisados, a fim de verificar a adequação do equipamento diante das condições efetivas de trabalho.

Palavras-chave: Espectroscopia de fluorescência de raios X. Arqueometria. Patrimônio cultural.

\section{Introdução}

A espectroscopia de fluorescência de raios X por energia dispersiva (EDXRF - EnergyDispersive X-Ray Fluorescence) é uma técnica não-destrutiva que permite a identificação e a quantificação de elementos a partir de um dado número atômico tipicamente a partir de $\mathrm{Na}$, em $\mathrm{He}$ ou vácuo, e de $\mathrm{Al}$, ao ar — em materiais de qualquer natureza.

Por não exigir vácuo e poder utilizar componentes de pequenas dimensões, o equipamento pode ser utilizado para análises in situ e não há limitações de tamanho 
para o objeto analisado. Além disso, para análises de superfícies, não há necessidade de retirada de amostras ou desbaste.

O princípio da técnica consiste em incidir raios $X$ sobre a região a ser analisada de modo a excitar os elementos presentes, que emitirão assim raios $X$ com energias características de cada elemento. As intensidades dos picos obtidos crescem com os teores dos elementos, permitindo, em certas condições, análises quantitativas.

Espectrômetros EDXRF portáteis comerciais podem ser muito úteis na identificação de ligas metálicas comerciais, na verificação de teores de elementos específicos nestas ligas, etc. $\mathrm{Na}$ área do patrimônio cultural, contudo, inúmeros pesquisadores (1) têm optado por desenvolver seus próprios equipamentos, para terem maior flexibilidade no uso de diferentes geometrias de análise, filtros, colimadores, alvos secundários, etc. O presente trabalho descreve um equipamento desenvolvido na Escola Politécnica da USP e seu uso na caracterização de peças de aço produzidas na primeira siderúrgica brasileira, a Usina de Ipanema (Figura 1), e de peças metálicas da coleção préhispânica do Museu de Arqueologia e Etnologia da USP (Figura 2). Para as peças de Ipanema, o principal interesse residiu na quantificação aproximada de titânio, presente nos minérios de ferro da região, e que se supõe ter sido um elemento deletério à qualidade destes aços $(2,3)$. Para as peças pré-hispânicas, compostas essencialmente de ligas ouro-cobre-prata (4), o interesse concentrou-se na identificação de eventuais elementos minoritários.

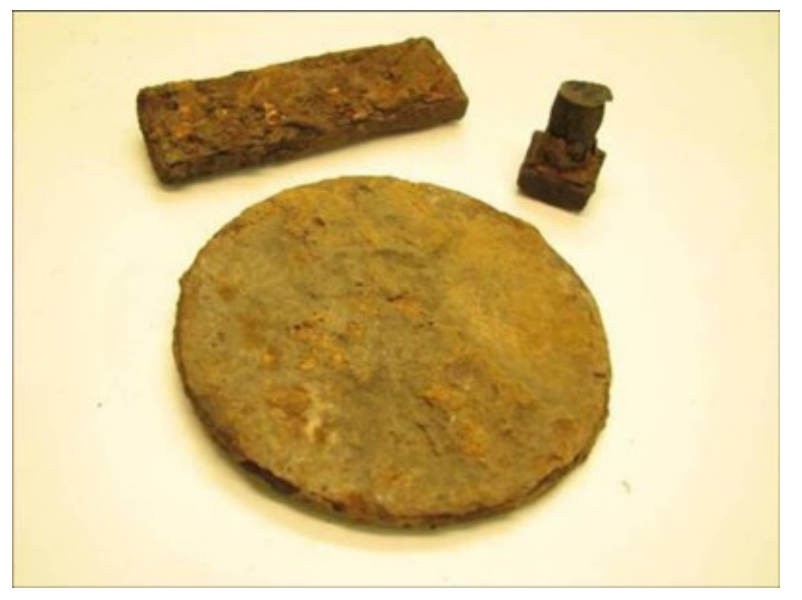

FIGURA 1 - Peças de aço da Usina de Ipanema. 

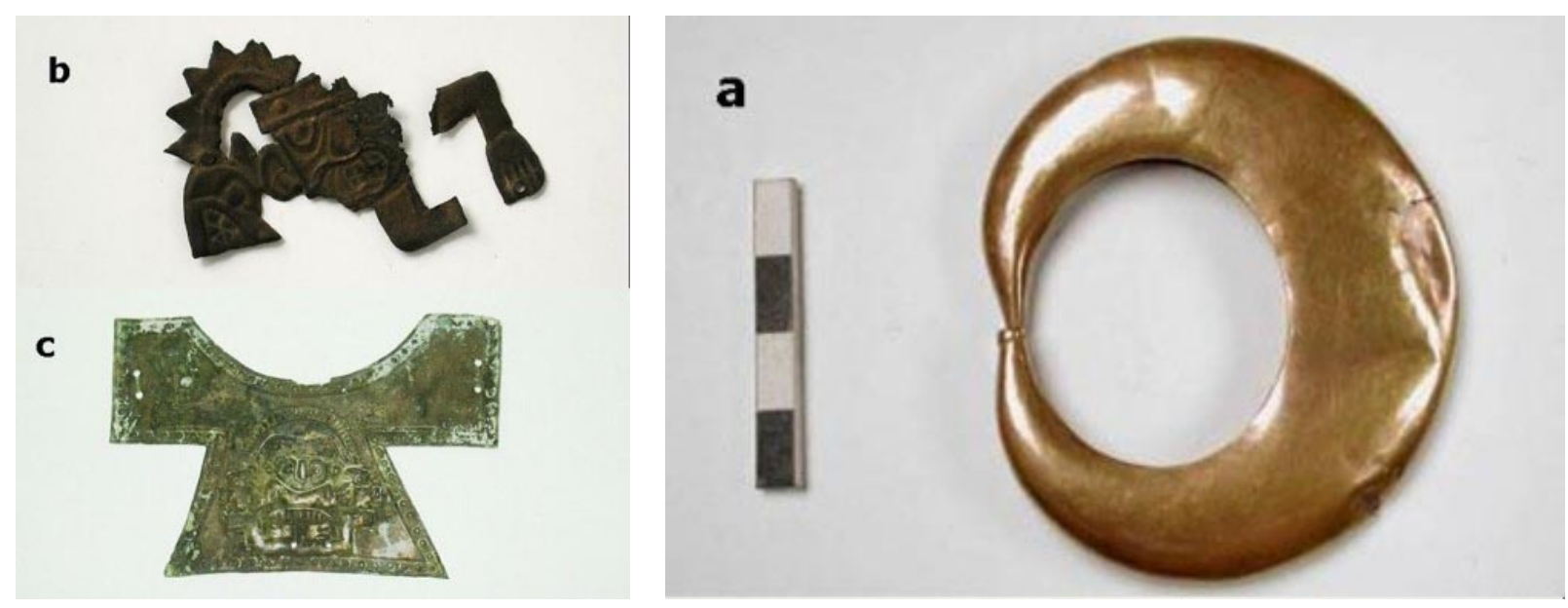

FIGURA 2 - Exemplos de peças metálicas da coleção pré-hispânica do MAE/USP: a) Brinco, origem não-registrada. b) Placa, proto-Chimu. c) Peitoral, Chimu. Fotos de Wagner Souza e Silva, MAE.

\section{Equipamento e métodos}

O equipamento consiste de um tubo de raios $\mathrm{X}$ da Ital Structures e um detector de raios $X$ da Ketek (Figura 3). $O$ tubo tem anodo de $W$ e opera em até $60 \mathrm{kV}$. Esta voltagem elevada permite a excitação de linhas $K$ até elementos razoavelmente pesados, evitando que nos limitemos às linhas $L$ ou $M$ destes elementos, que são mais fracas $e$ menos diferenciadas e que podem estar sobrepostas a outras linhas de elementos mais leves. Esta vantagem é ilustrada na Figura 4, que apresenta linhas $\mathrm{K}$ e $\mathrm{L}$ de $\mathrm{Sn}$ e Sb. Por serem vizinhos na Tabela Periódica, suas linhas equivalentes são também vizinhas. Como se observa na figura, a quantificação das mesmas é muito mais precisa na série $\mathrm{K}$ que na $\mathrm{L}$. A corrente máxima do tubo, 1,5 mA, também é elevada, correspondendo a um fluxo elevado de fótons.

Para isso, o tubo tem dimensões maiores que as dos tubos usualmente utilizados nos espectrômetros portáteis. Esta desvantagem é contrabalançada pela possibilidade de se obter um fluxo razoável mesmo com colimadores finos ou com alvos secundários. 


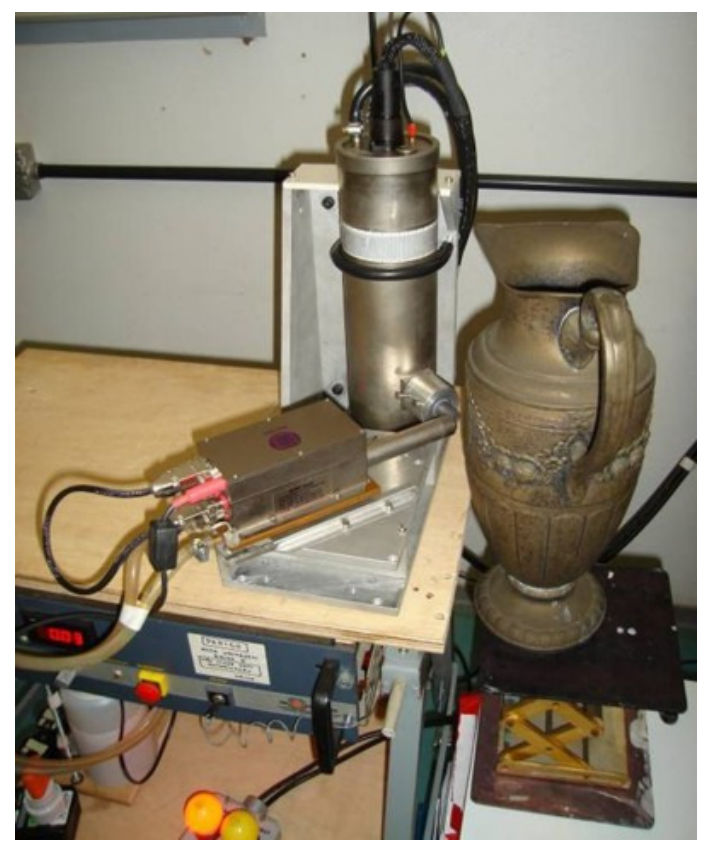

FIGURA 3 - Espectrômetro.

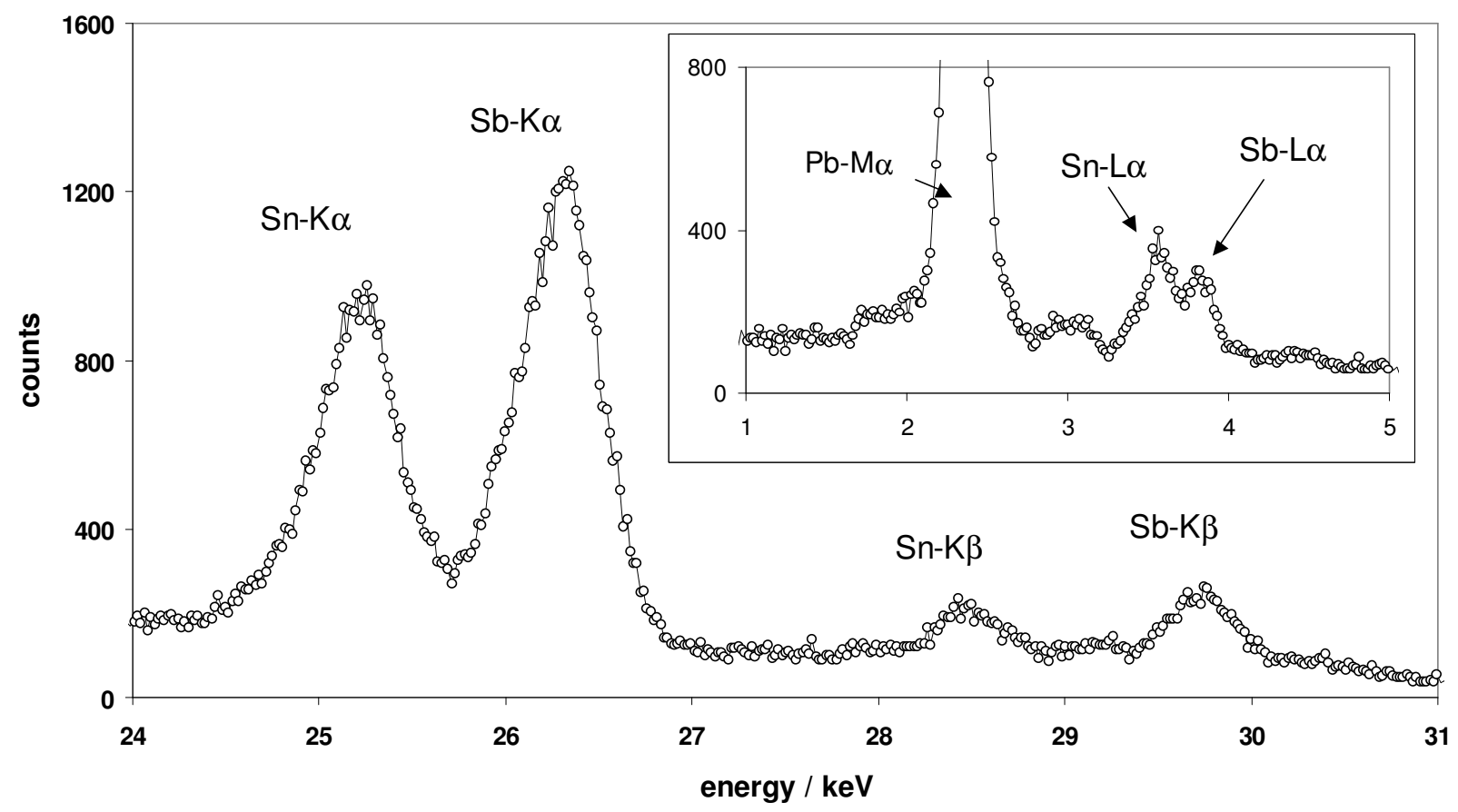

FIGURA 4 - Espectro de liga Pb-Sn-Sb rica em Pb. O gráfico principal mostra linhas $\mathrm{K}$ de $\mathrm{Sn}$ e $\mathrm{Sb}$. O gráfico secundário mostra linhas $L$ de $S n$ e $\mathrm{Sb}$, bem como uma linha $\mathrm{M}$ de $\mathrm{Pb}$.

O detector utilizado é do tipo Si-drift, que permite elevada resolução de energia. Ele dispõe de resfriamento pelo sistema Peltier, que dispensa o uso de nitrogênio líquido. 
O sistema permite $\mathrm{O}$ uso de diferentes ângulos entre o feixe de incidência e de detecção, e diferentes distâncias amostra-detector. Na maioria das medidas, foi utilizado um ângulo de $90^{\circ}$ entre os feixes, e uma distância de $8 \mathrm{~mm}$ entre amostra e detector. Esta pequena distância permite que seja pequena a absorção do feixe pelo ar e que o pico de argônio, do ar, seja pequeno. Para facilitar o posicionamento correto do ponto a ser analisado, o sistema dispõe de um par de apontadores laser, bem como de uma pequena webcam.

Para a maioria das análises, foi utilizado um colimador de chumbo para o feixe incidente, com diâmetro de 1,4mm. Foram feitos diversos ensaios para identificação, quantificação e controle de picos espúrios intrínsecos, gerados pelo detector (picosescape e picos-soma), ou extrínsecos, originados dos colimadores do tubo e do detector (picos de $\mathrm{Pb}$ e $\mathrm{Zr}$, respectivamente).

As peças pré-colombianas estavam isentas de camadas substanciais de corrosão. As de aço, pelo contrário, estavam recobertas por uma camada substancial e foram analisadas sem remoção da mesma. Uma das peças, contudo, fora previamente seccionada, o que permitiu análises de sua região interna.

Nos ensaios dos aços, utilizou-se um alvo secundário de cromo, com objetivo de promover excitação preferencial do titânio, cujos picos K- $\alpha$ ficam muito próximos dos picos-escape de Fe K- $\alpha$, dificultando sua quantificação. Com o arranjo, a intensidade relativa $\mathrm{Ti} / \mathrm{Fe}$ cresceu cerca de 2,3 vezes (Figura 5), permitindo uma melhor determinação da área do pico de Ti: a incerteza relativa caiu de $17 \%$ para $6 \%$. Foi escolhido o cromo como alvo porque suas linhas $\mathrm{K}-\alpha$ e K- $\beta$ encontram-se abaixo da borda de absorção $\mathrm{K}$ do $\mathrm{Fe}$ e acima da borda de absorção $\mathrm{K}$ do Ti e, portanto, excitam Ti mas não excitam Fe. 

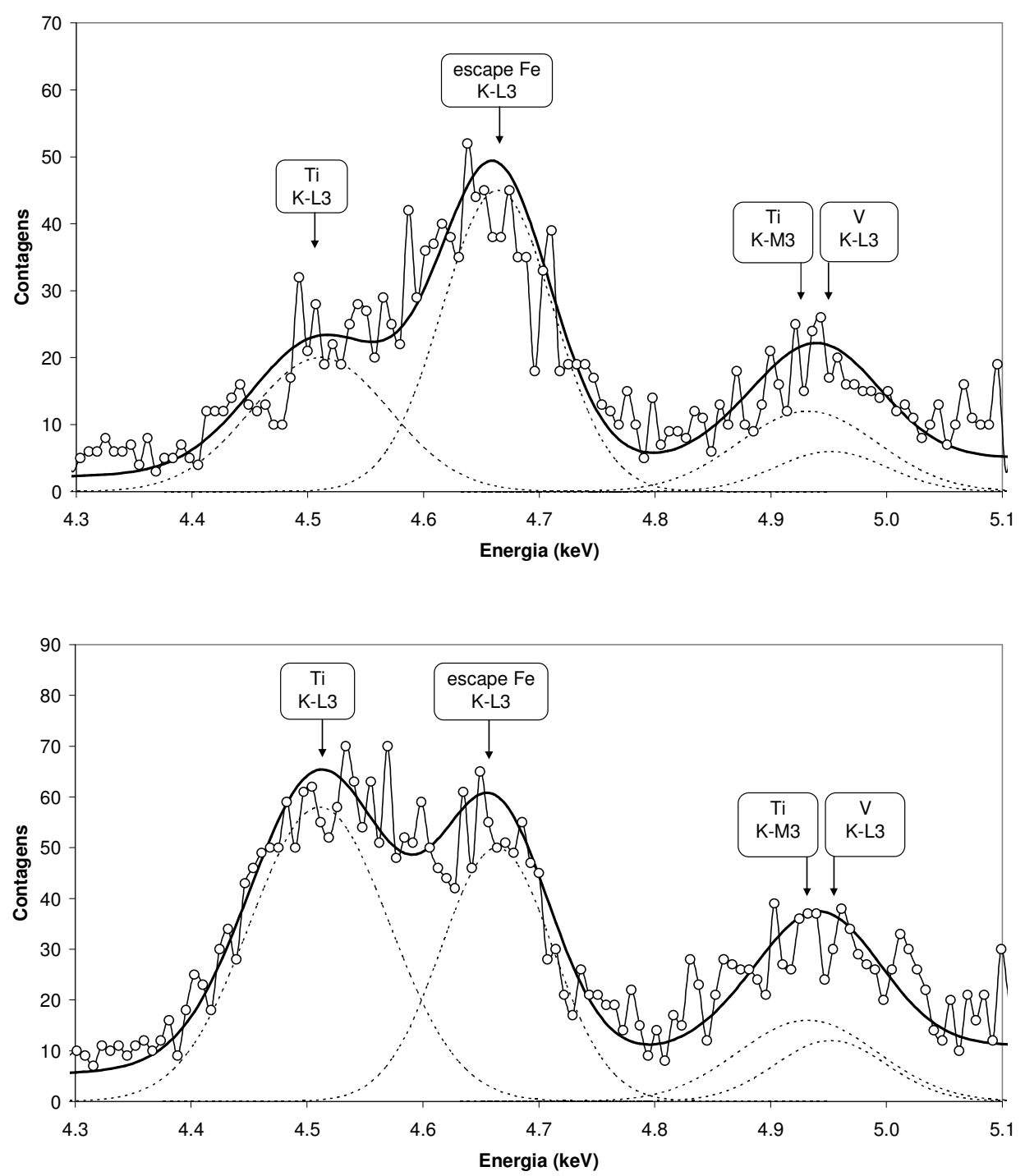

FIGURA 5 - Região do pico de Ti K- $\alpha$ de espectros obtidos com o arranjo normal (em cima) e com o uso de alvo secundário de cromo (em baixo).

\section{Resultados}

\section{a) Ti nas peças de lpanema e nos padrões NBS}

A Figura 6 mostra o espectro obtido na superfície do disco da Figura 1. Observam-se picos de $\mathrm{Ca}, \mathrm{P}, \mathrm{Ti}, \mathrm{Cr}, \mathrm{Mn}, \mathrm{Fe}, \mathrm{Ni}, \mathrm{Cu}, \mathrm{Zn}, \mathrm{Pb}$ and $\mathrm{Zr}$. Verificou-se que os picos de $\mathrm{Pb}$ e $\mathrm{Zr}$ provêm apenas dos colimadores. Observa-se, no destaque, que o pico Ti K- $\alpha$ fica parcialmente superposto ao pico de escape de Fe K- $\alpha$, o que aumenta, como já mencionado, a incerteza de medida em sua área. Concentramo-nos por isso nos 
ensaios feitos com alvo secundário de cromo. Para comparação, um conjunto de amostras-padrão de aços baixa-liga NBS foi também medido, obtendo-se uma relação praticamente linear entre as áreas e as concentrações de titânio (para aços com elevados teores de cromo, no entanto, esta relação linear não foi obtida, uma vez que a fluorescência secundária deste metal provoca um forte reforço nas linhas $K$ do titânio). Com base nesta relação, pode-se estimar que o teor de Ti na seção do pino é da ordem de $0,2 \%$. Na análise desta mesma peça na região não-preparada, obteve-se um pico de $\mathrm{Ti}$ com área 5,6 vezes menor, uma vez que a camada externa absorve substancialmente as radiações $\mathrm{K}$ de Ti. Se considerarmos - como uma aproximação - que a absorção efetuada pela camada externa do disco é semelhante à observada no pino, podemos concluir que o teor de Ti no disco é da ordem de $1 \%$, uma vez que no disco seu pico tinha área cerca de cinco vezes maior que no pino.

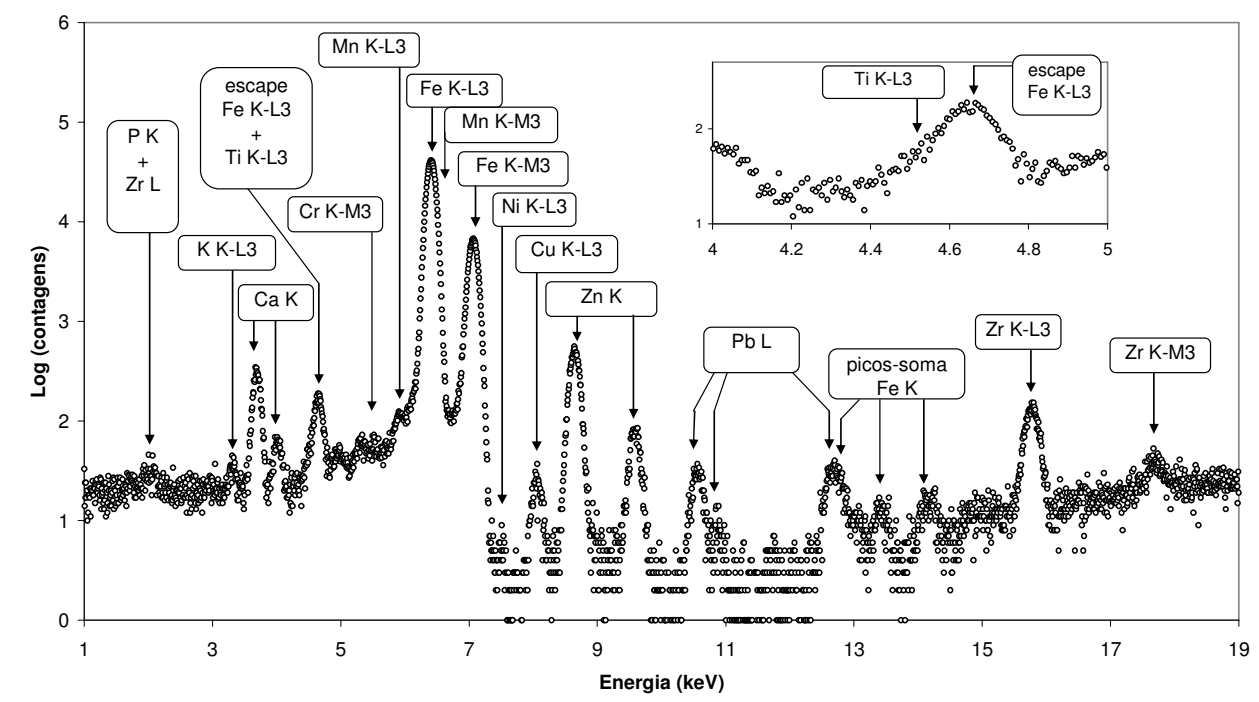

FIGURA 6 - Espectro obtido na superfície do disco da Figura 1.

\section{b) Peças pré-colombianas}

A Figura 7 apresenta espectros das três peças mostradas na Figura 2. Elas são ricas principalmente em ouro, em cobre e em prata/cobre, respectivamente. Nos dois primeiros espectros, verificou-se que os picos de $\mathrm{Zr}$ e de $\mathrm{Pb}$ provinham apenas dos colimadores. Portanto, o ornamento nasal contém apenas $\mathrm{Au}, \mathrm{Ag}$ e $\mathrm{Cu}$, e a placa Huari 
contém $\mathrm{Cu}, \mathrm{Ag}, \mathrm{Au}, \mathrm{Fe}$ e $\mathrm{Ca}$. No peitoral Chimu, ao contrário, os picos de Pb provinham também da própria peça. Assim, ela continha $\mathrm{Ag}, \mathrm{Cu}, \mathrm{Au}, \mathrm{Fe}$ e $\mathrm{Pb}$. Consistentemente, em todas as vinte peças analisadas, as únicas peças que não apresentaram elementos além de $\mathrm{Au}$, Cu e Ag eram de origem inca.

Para estas peças, não procuramos obter resultados quantitativos, uma vez que a preparação de superfície realizada pelas civilizações pré-colombianas usualmente se baseava na dissolução seletiva de elementos de liga de modo a serem obtidos diferentes efeitos de cor a partir das diferentes composições atingidas na superfície. A maioria destas peças, portanto, apresenta um gradiente de composição da superfície em direção às partes internas. Assim, a análise química superficial corresponde a médias, com um peso relativo decrescente da superfície em direção às regiões internas, e valores quantitativos poderiam não ter significado.

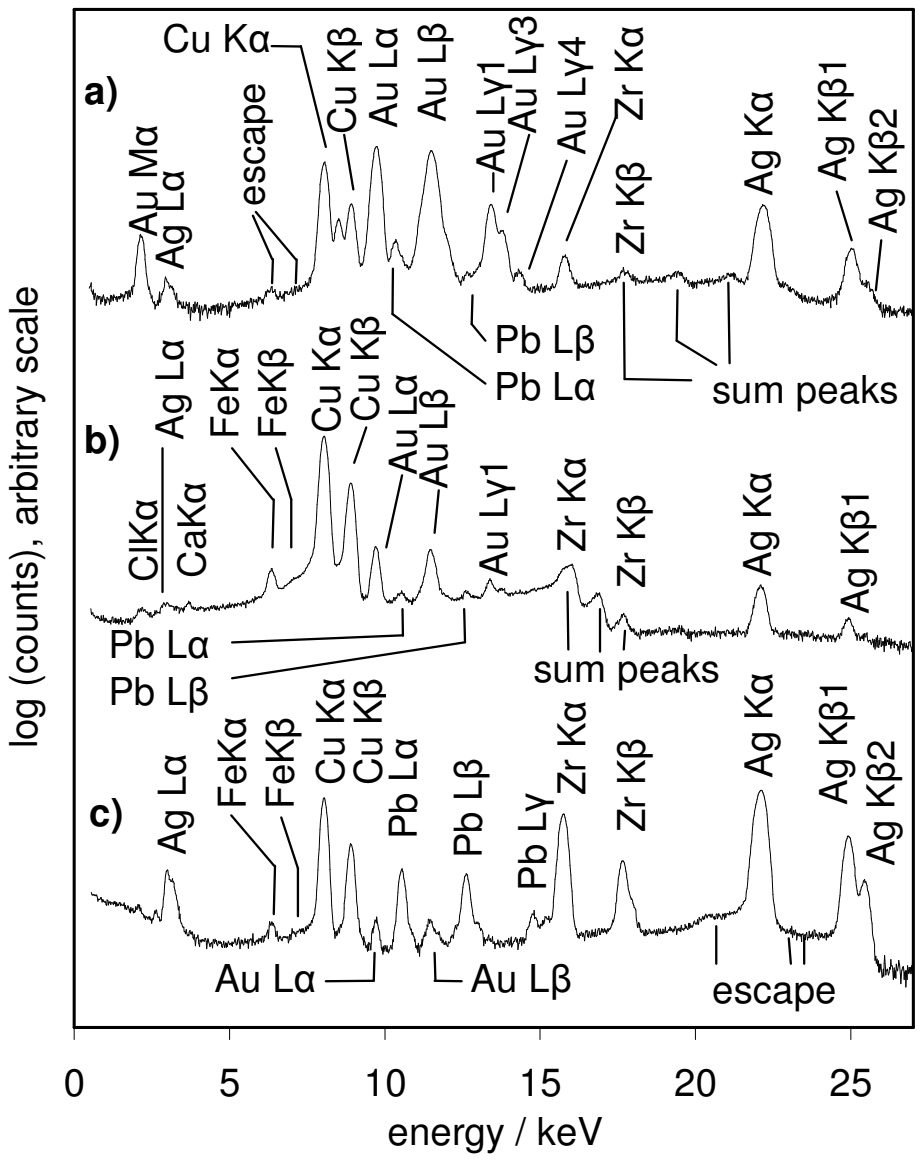

FIGURA 7 - Espectros das três peças apresentadas na Figura 2: a) Brinco; b) Placa; c) Peitoral. 


\section{Conclusões}

O espectrômetro construído na EPUSP mostrou-se extremamente adequado para identificação e quantificação de elementos médios e pesados. Os picos espúrios, inerentes a qualquer sistema do gênero, foram analisados, quantificados e controlados. O uso de alvo secundário de cromo permitiu uma adequada determinação da área dos picos K- $\alpha$ de Ti em situação crítica — correspondente a baixos teores de Ti e elevados teores de $\mathrm{Fe}$ - na qual o pico de Ti fica parcialmente sobreposto pelo pico-escape de Fe K- $\alpha$. Desta forma, conseguiu-se determinar um teor aproximado de Ti em amostras de aço da Usina de Ipanema.

Elementos minoritários adicionais nas ligas Au-Cu-Ag pré-hispânicas do MAE foram também identificados. Estes resultados mostram a adequação do equipamento para análises in situ de superfícies, sem retirada de amostras.

Como continuidade desta linha de trabalho, vêm sendo realizadas análises em moedas brasileiras, em ferragens oitocentistas e em peças não-metálicas, como fragmentos de pinturas murais oitocentistas (5) e ladrilhos hidráulicos. Além disso, está sendo desenvolvido (3) um software baseado em parâmetros fundamentais para a realização de análises quantitativas.

\section{Referências Bibliográficas}

(1) CANEVA C.; FERRETTI M. XRF spectrometers for non-destructive investigations in art and archaeology: the cost of portability. In: WORLD CONFERENCE ON NON-DESTRUCTIVE TESTING, 15., 2000, Rome, Italy. Proceedings...p. 15-23. Disponível em:

http://www.ndt.net/article/wcndt00/papers/idn680/idn680.htm. Acesso em: 19 maio 2008.

(2) FELICÍSSIMO JR, J. História da Siderurgia de São Paulo: seus personagens, seus feitos. [S.I.]: Associação Brasileira de Metais, 1969.

(3) NEIVA A. C.; DRON J. N.; LOPES B. F.; APPOLONI C. R.; PARREIRA P. S.; TSCHIPTSCHIN A., P.; LANDGRAF F. [ ]. In: SIMPÓSIO LATINO AMERICANO SOBRE MÉTODOS FÍSICOS E QUÍMICOS EM ARQUEOLOGIA, ARTE E CONSERVAÇÃO DO PATRIMÔNIO CULTURAL, 1., 2007, São Paulo. Programa e Resumos. São Paulo: Sociedade Brasileira de Física, 2007. p. 68.

(4) NEIVA, A. C. ; DRON, Jérémie Nicolae; LIMA, Sílvia Cunha. Considering spurious peaks in the EDXRF analysis of metallic pre-Columbian pieces of the Museum of Ethnology and Archaeology of the University of Sao Paulo. In: HERITAGE, WEATHERING AND CONSERVATION INTERNATIONAL CONFERENCE, 2006, Madrid. Proceedings... Leiden: Taylor \& Francis, 2006. v. 2. p. 605-611. 
(5) TIRELLO, R. A. ; NEIVA, A. C. ; J.N.Dron ; LOPES, B. F. Caracterização por EDXRF de pigmentos brancos em fragmentos de pinturas murais oitocentistas do ciclo do café no Vale do Paraíba (resumo). In: LASMAC LATINAMERICAN SYMPOSIUM ON PHYSICAL AND CHEMICAL METHODS IN ARCHAEOLOGY, ART AND CULTURAL HERITAGE CONSERVATION, 1., 2007, São Paulo = SIMPOSIO LATINO AMERICANO SOBRE MÉTODOS FÍSICOS E QUÍMICOS EM ARQUEOLOGIA, ARTE E CONSERVAÇÃO DE PATRIMÔNIO CULTURAL, 1. Programa e Resumos. São Paulo: LASMASC, SBF, IF-USP, 2007. v. 1. p. 66.

* Professor da Escola Politécnica da USP, Doutor em Engenharia de Materiais,com pós-doutorado na Universidade de Birmingham (Inglaterra).

e-mail: acneiva@usp.br

** Jérémie Nicoläe Dron - Pesquisador na Escola Politécnica da USP, Bacharel em Física pela Université d'Evry Val d'Essonne (França), com DEA no Museu do Louvre.

e-mail: jeremie.dron@gmail.com

Os autores agradecem ao CNPq e à FAPESP pelo apoio financeiro para a realização deste trabalho. 